319/9s (2)

PPPL-2787

UC-427
PREPARED FOR THE U.S. DEPARTMENT OF ENERGY, UNDER CONTRACT DE-AC02-76-CHO-3073

PPPL-2787

NONLOCAL HEAT TRANSPORT IN

A STOCHASTIC MAGNETIC FIELD

BY

J.M. RAX AND R.B. WHITE

December 1991
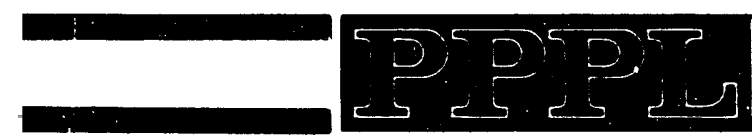

paINCETON

plazma phybics

Lägátogr

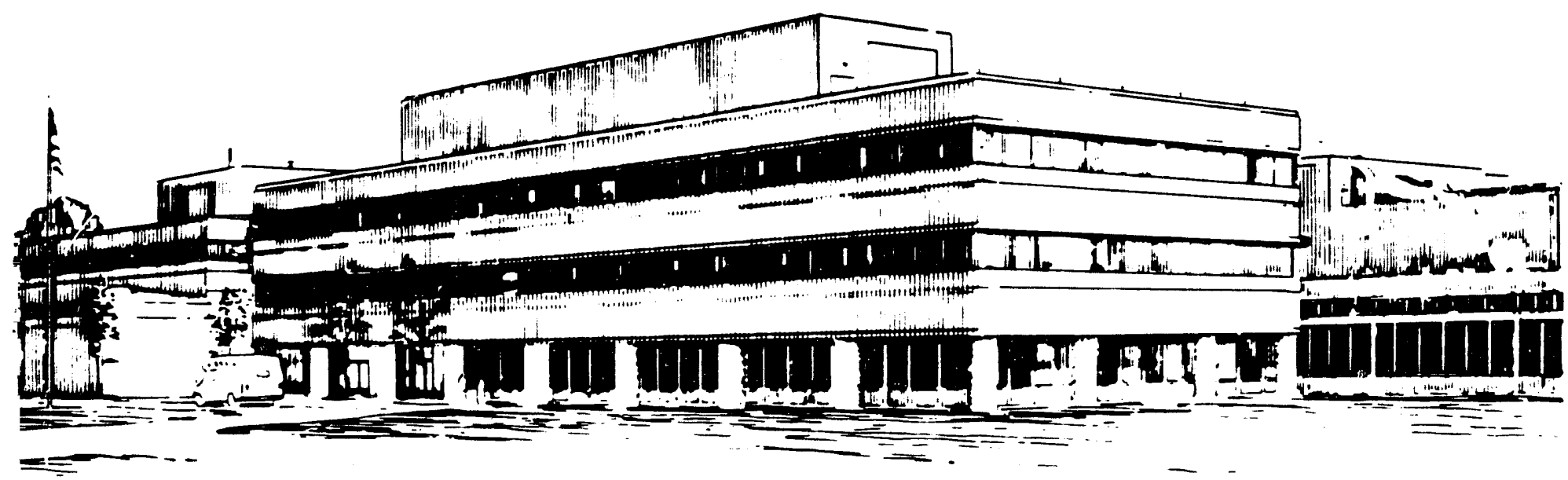

PRINCETON UNIVERSITY, PRINCETON, NEW JERSEY 
This report was prepared as an account of work sponsored by an agency of the United States Government. Neither the United States Government nor any agency thereof, nor any of their employees, makes any warranty, express or implied, or assumes any legal liability or responsibility for the accuracy, completeness, or usefulness of any iniormation, apparatus, product, or process disclosed, or represents that its use would not infringe privately owned rights. Reference herein to any specific commercial produce, process, or service by trade name, trademark, manufacturer, or otherwise, does not necessarily constitute or imply its endorsement, recommendation, or favoring by the United States Government or any agency thereof. The views and opinions of authors expressed herein do not necessarily state or reflect those of the United States Government or any agency thereof.

\section{NOTICE}

This report has been reproduced directly from the best available copy.

Available to DOE and DOE contractors from the:

Office of Scientific and Technical Information

P.O. Box 62

Oak Ridge, TN 37831 ;

Prices available from (615) 576-8401.

Available to the public from the:

National Technical Information Service

U.S. Department of Commerce

5285 Port Royal Road

Springtield, Virginia 2216i

703-487-4650 


\title{
NONLOCAL HEAT TRANSPORT IN A STOCHASTIC MAGNETIC FIELD
}

\author{
J.M. Rax ${ }^{\dagger}$ and R.B. White \\ Princeton Plasma Physics Laboratory, Princeton University, Princeton N.J. 08543
}

\begin{abstract}
Heat transport in a stochastic magnetic field configuration is shown to be nonlocal. Cullisional transport processes, in such a disordered media, cannot always be reduced to a standard diffusion process, and the concept of a diffusion coefficient is meaningless for a wide range of typical tokamak parameters. In the nonlocal regime the relaxation of a gradient is described by an integral equation, involving a nonlocal propagator. This propagator is calculated, and the relation to previous results is elucidated.
\end{abstract}

${ }^{\dagger}$ Permanent adress: Association EURATOM-CEA sur la Fusion Consrôlée, 13108 Saint-Paul-lez-Durance, France.

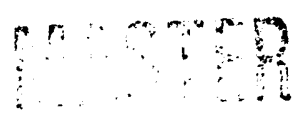


A three dimensional toroidal magnetic field is a Hamiltonian system, and the existence of magnetic surfaces in an axisymmetric configuration is a consequence of the KolmogorovArnold-Moser stability theorem. The occurrence of small resonant magnetic field perturbations can lead to the onset of chaotic field line diffusion, ${ }^{1}$ provided that the Chirikov criterion is fullfilled. This deconfinement mechanism has been recognized as a candidate to explain anomalous confinement properties of Tokamak discharges, ${ }^{24}$ and can be used to control the edge characteristics with ergodic divertor configurations. ${ }^{5}$

This letter addresses the problem of heat transport in such random fields (the results also apply to particle transport in the strong collisionality regime), and stresses the fact that models based on local diffusion cannot be used in a wide range of typical tokamak parameters. Nonlocal responses in plasma physics have already been used to study heat transport during laser plasma interaction, ${ }^{6}$ current transport in Reversed Field Pinch configurations, ${ }^{7}$ and in wave driven Tokamaks. ${ }^{8}$ Nonlocality in a braided magnetic field was noted by Stix ${ }^{3}$ but there was no attempt to calculate the anomalous mean squared displacement, and to relate it to a nonlocal propagator.

On the basis of a Lagrangian formulation, with Langevin equations, we show that transport cannot always be reduced to a diffusion. The relevant theoretical framework needed to describe the collisional regime in a stochastic magnetic field is an integral rather than a differential equation. The nonlocal propagator of this integral equation is calculated with the help of a Wiener 'unctional integral over the random magnetic field. Finally a direct numerical simulation is perfo.med to confirm the analytical results.

The most general, (linear, causal) transport theory of a passive scalar, $T(r, t)$ (temperature or density), in a statistically homogeneous media, is nonlocal and relates $T$ at point $\mathbf{r}$, time $t$, to the source, $S\left(r^{\prime}, t^{\prime}\right)$, elsewhere before $t$, through a propagatur $P$ :

$$
T(r, t)=\int d t^{\prime} d r^{\prime} P\left(r-r^{\prime}, t-t^{\prime}\right) S\left(r^{\prime}, t^{\prime}\right) .
$$

$P$ is the fundamental quantity arising through first principles, the diffusion coefficient is not fundamental and may or may not exist. Let us consider the long distance behavior of 
the Fourier transform, $P(k, \omega)$, of $P(r, t)$. If its asymptotic form for large $\mathbf{r}$ and $t$, i.e., near $\mathbf{k}=\mathbf{0}$, and $\omega \approx 0$, is

$$
\mathrm{P}^{-1}(\mathbf{k}, \omega) \sim \mathrm{i} \omega+\mathbf{k} \cdot \mathbf{D} \cdot \mathbf{k}+\ldots,
$$

then the transport becomes local and diffusive on large space and time scales. T obeys the usual differential equation, and the mean squared displacement $\langle\mathbf{r}(\mathrm{t}) \mathbf{r}(\mathrm{t})\rangle=2 \mathbf{D} \mathrm{t}$ is normal. Good analytical properties of $\mathrm{P}^{-1}$ near $\mathbf{k} \approx 0$ and $\omega \approx 0$ are thus required for local diffusion to be well defined.

Recently a large number of physical problems such as diffusion in convective cells, ${ }^{9}$ diffusion on stochastic webs, ${ }^{10}$ diffusion on percollating clusters, ${ }^{11}$ convection of a passive scalar by a turbulent flow, diffusion in disordered media, or on various kinds of fractal structures, ${ }^{12}$ have displayed anomalous mean-squared displacement

$$
\left\langle r^{2}(t)\right\rangle \sim t^{\alpha} .
$$

The exponent, $\alpha$, characterizing the fractional Brownian motion ${ }^{13}$ can be larger or smaller than one, with trapping or long ballistic flights often the cause of this subdiffusive or hyperdiffusive transport. When $\alpha \neq 1$, an application of the definition of the diffusion coefficient will give 0 or $+\infty$. This does nct mean that the diffusion is 0 or $+\infty$, it means that the concept of diffusion coefficient is meaningless, and that the expansion Eq.( 2 ) does not give a simple formula.

In the problem of fast heat diffusion along a magnetic field line combined with a Brownian wandering of this line, and a very slow collisional diffusion across the line, the exact solution of the associated Langevin equation, gives a stochastic transport across the main field with $\alpha=1 / 2$, and the additional normal, $\alpha=1$, collisional term is often negligible compared to the anomalous displacement. This solution will also display the fact that, as far as the mean-squared displacement is concerned, there are no couplings of the perpendicular purely collisional dynamics with the other processes. Thus effective diffusion coefficients $D_{\text {eff }}$ involving parallel, perpendicular and magnetic diffusion are not directly recovered. Moreover the final result of the analysis is that, in many typical tokamak conditions, instead of a propagator of the usual local type $\mathrm{P} \sim \exp \left[-\mathrm{r}^{2} / \mathrm{D}_{\text {eff }} \mathrm{t}\right]$ the 
propagator behaves as $\mathrm{P} \sim \exp \left[-\mathrm{r}^{4 / 3} / \mathrm{t}^{1 / 3}\right]$, thus ruling out any attempt to define an effective diffusion coefficient.

Consider an infinite homogeneous magnetic field $\mathbf{B}$ directed along the $\mathrm{z}$ axis, and a small random field, $\mathbf{b}$, such that $\langle\mathbf{b}\rangle=\mathbf{0}, \nabla \cdot \mathbf{b}=0$, and $\left\langle\mathbf{b}^{2}\right\rangle / \mathrm{B}^{2}$ is a small parameter of the order of $10^{-6}-10^{-8}(<>$ indicates statistical averages $)$, the component $\mathbf{B} \cdot \mathbf{b}$, if any, is completly irrelevant to the problem. The second moments of the $\mathbf{b}$ field are characterized by the longitudinal ( $z$ ) correlation length, $\lambda_{\|}$, and the transverse $(x, y)$ one, $\lambda_{\perp}$ (the $x$ and $y$ variables describe a local slab frame near the braided magnetic surfaces). The tokamak geometry consists of nested toroidal surfaces with field lines traversing the poloidal angle, thus the statistical average is to be completed by a poloidal average. As noted by Kadomtsev and Pogutse ${ }^{4}$ there exist two regimes of magnetic field line diffusion, the quasilinear one, when $\lambda_{\|} b<\lambda_{\perp} B$, and the nonlinear one. Most studies have been restricted to the former, the ordering relevant for stochastic field line diffusion induced by resonant perturbations in a tokamak. Thus disregarding the $x$ and $y$ dependence of the moments compared to that in $z$, we consider the following Gaussian random field $\left\langle b_{x}(z) b_{x}\left(z^{\prime}\right)\right\rangle=$ $\left\langle b_{y}(z) b_{y}(z)\right\rangle=\left\langle b^{2}\right\rangle \exp \left[-\left(z-z^{\prime}\right)^{2} 2 \lambda_{11}^{2}\right]$ (the influence of transverse correlations is assessed at the end of the paper). This is the standard model of magnetic field line diffusion and the magnetic diffusion coefficient $\chi_{M}$ is:

$$
\chi_{M}=\sqrt{\pi / 2} \lambda_{\|}\left\langle b^{2}\right\rangle / B^{2}
$$

We call $\chi_{\|}$and $\chi_{\perp}$ the temperature (or density, if particle transport is diffusive rather than ballistic along one parallel correlation length) diffusion coefficients due to collisions, along and across the field. The correlation time of $\mathbf{b}$ is larger than the toroidal transit time of a thermal electron; thus b can be treated as static. This usual assumption is relevant to ergotic divertor configurations which are static, and to magnetic turbulence with frequency typically of the order of the electron diamagnetic frequency. The temperature diffusion equation is equivalent to Langevin equations, Eqs.(5), (6), (7):

$$
\frac{d x}{d t}=\frac{d z}{d t} \frac{b_{x}}{B}+\eta_{\perp}
$$




$$
\begin{gathered}
\frac{d y}{d t}=\frac{d z}{d t} \frac{b y}{B}+\eta_{\perp}, \\
\frac{d z}{d t}=\eta_{\| l} .
\end{gathered}
$$

The Lagrangian coordinates $(x, y, z)$ describe pseudo-particles whose Eulerian average is the temperature distribution. The statistical characteristics of the collisional noises $\eta$ are $\left\langle\eta_{\perp}(t)\right\rangle=0,\left\langle\eta_{\perp}(t) \eta_{\perp}\left(t^{\prime}\right)\right\rangle=2 \chi_{\perp} \delta\left(t-t^{\prime}\right),\left\langle\eta_{\|}(t)\right\rangle=0,\left\langle\eta_{\| 1}(t) \eta_{\|}\left(t^{\prime}\right)\right\rangle=2 \chi_{\| 1} \delta\left(t-t^{\prime}\right)(\delta$ is the Dirac distribution). Thus when $\mathbf{b}=\mathbf{0}$, we recover collisional fast diffusion along $\mathbf{B}$, and very slow diffusion across $\mathbf{B}$. Because of the very small value of the perturbing field we have neglected the difference between the curvilinear distance along the field line and the $z$ coordinate $\left(d s=\sqrt{d x^{2}+d y^{2}+d z^{2}}=d z+O\left[\left\langle b^{2}\right\rangle / B^{2}\right]\right)$. Let us introduce $b(k)$, the Fourier transform of $\mathbf{b}(z)$, and integrate Eqs. (5), (6), (7) to obtain $r^{2}=x^{2}+y^{2}$ as follows:

$$
\left\langle\mathrm{r}^{2}(\mathrm{t})\right\rangle=\int \frac{\mathrm{dk}}{\mathrm{k}} \frac{\mathrm{dk} \mathbf{k}^{\prime}}{\mathrm{k}^{\prime}}\left\langle\frac{\mathbf{b}(\mathrm{k}) \cdot \mathrm{b}^{*}\left(\mathrm{k}^{\prime}\right)}{\mathrm{B}^{2}}\right\rangle\left\langle\left[\mathrm{e}^{\mathrm{ikz}(\mathrm{t})}-1\right]\left[\mathrm{e}^{\mathrm{ikz}(\mathrm{t})}-1\right]\right\rangle+\int^{\mathrm{t}} \mathrm{dudu} \mathrm{u}^{\prime}\left\langle\eta_{\perp}(\mathrm{u}) \eta_{\perp}\left(\mathrm{u}^{\prime}\right)\right\rangle .
$$

Even if there are correlations between $\eta_{\| 1}(t)$ and $\eta_{\perp}\left(t^{\prime}\right)$ the fact that $\langle\mathbf{b}\rangle=0$ leads to the cancellation of cross terms of the type $\eta_{\perp} b$. Using the Gaussian properties of the collisional noise $\left\langle e^{i k z(t)}\right\rangle=e^{-k^{2} x_{\| t} t^{t}}$ and $\left.\left\langle b_{x}(k) b_{x}^{*}\right)\left(k^{\prime}\right)\right\rangle=\left\langle b_{y}(k) b_{y}^{*}\left(k^{\prime}\right)\right\rangle=\left\langle b^{2}\right\rangle \lambda_{\|} \delta\left(k-k^{\prime}\right)$ $\exp \left[-\mathrm{k}^{2} \lambda_{1 /}^{2} / 2\right] / \sqrt{2 \pi}$ we obtain the mean squared displacement :

$$
\left\langle\mathrm{r}^{2}(\mathrm{t})\right\rangle=\frac{8}{\sqrt{\pi}} \chi_{M} \sqrt{\chi_{\| 1} \mathrm{t}}+4 \chi_{\perp} \mathrm{t} .
$$

No effective diffusion coefficient $D_{\text {eff }}\left(\chi_{M} \cdot \chi_{\| 1}, \chi_{\perp}, \lambda_{\| \mid}\right)$is found with the exact solution of the Langevin equation. On the basis of Eq.(9) two transpor regimes are to be considered. For a given length $r$, if the first term on the right hand side dominates, we must accept the scaling $\left\langle\mathrm{r}^{2}(\mathrm{t})\right\rangle=8 \chi_{M} \sqrt{\chi_{\| t} \mathrm{t} / \pi}$ and not try to define an effective local diffusivity, but explain the transport in term of a nonlocal propagator. When the anomalous $\sqrt{t}$ is smaller than the normal term an effective diffusion coefficient $D_{\text {eff }}$ can be constructed, following the analysis proposed by Rechester and Rosenbluth, ${ }^{2}$ provided that an additional mechanism like the exponential stretching of a stochastic instability is present, but such a mechanism does not exist for a pure random field. 
The collisional diffusion coefficients scale differently with respect to density $\mathrm{n}$, and temperature $T: \chi_{\|} \sim T^{5 / 2} n^{-1}, \chi_{\perp} \sim T^{-1 / 2} n$, so that in tokamaks we obtain a wide range of values: $\chi_{1 \mid}-10^{9}-10^{10} \mathrm{~m}^{2} / \mathrm{s}, \chi_{\perp} \sim 10^{-1}-10^{-2} \mathrm{~m}^{2} / \mathrm{s}$. The typical width of braided magnetic domain is $\mathrm{r} \sim 10^{-1}-1 . \mathrm{m}$, and $\chi_{\mathrm{M}} \sim 10^{-5}-10^{-8} \mathrm{~m}$. Thus nonlocal transport is dominant in many situations, including the case of an ergodic divertor in a low density edge plasma, and that of localized braiding near resonant magnetic sufaces leading to a small stochastic layer. The cases of large scale stochasticity or of very small perturbations in a dense plasma fall in the second regime.

In the following we consider the first regime and neglect the ineffective slow transverse purely collisional transport due to $\chi_{\perp}$. To describe heat diffusion along the random field lines, and to calculate the propagator associated with the dominant $\sqrt{t}$ scaling we shall use a functional Wiener integration. ${ }^{14}$ The probability to go from the point $(0,0,0)$, to the point $(x, y, z)$, in a time $t$, averaged over all the realizations of the stochastic field lines, is given by the functional integral:

$$
\mathrm{P}(\mathrm{x}, \mathrm{y}, \mathrm{z}, \mathrm{t})=\int_{(0,0,0)}^{(\mathrm{x}, \mathrm{y}, \mathrm{z})} D[x(\mathrm{u})] D[y(\mathrm{u})] \mathrm{P}_{1}[x(\mathrm{u}), y(\mathrm{u})] \mathrm{P}_{2}[x(\mathrm{u}), y(\mathrm{u}), \mathrm{t}] .
$$

$\mathrm{P}_{1}$ is the probability of a particular realization of a given line, $x(u), y(u)$, linking $(0,0,0)$ and $(x, y, z)$, and $P_{2}$ is the probability to diffuse from $(0,0,0)$ to $(x, y, z)$ in a time $t$, along this particular realization. $D[x(\mathrm{u})], D[y(\mathrm{u})]$ stand for the functional integration over all the realizations of the random field. Within the quasilinear approximation, the field lines are described by a diffusion equation so that $P_{1}$ is given by the usual Gaussian formula: ${ }^{14}$

$P(x, y, z, t)=\Theta(t) \int \frac{D[x(u)] D[y(u)]}{\sqrt{4 \pi \chi_{\|} t}} e^{\frac{-1}{4 \chi_{M}}} \int_{0}^{z} d u\left([d x / d u]^{2}+[d y / d u]^{2}\right) \frac{-1}{e^{4 \chi_{\| l}}}\left[\int_{0}^{z} \sqrt{d u^{2}+d x^{2}+d y^{2}}\right]^{2}$.

$\Theta(t)$ is the Heaviside step function ensuring causality. This formula exactly describes collisional diffusion along stochastic magnetic field lines, the field average heing achieved 
by th: first exponential $P_{1}$ and the collisional diffusion being described by the second one $P_{2}$. If we expand the exponent of this second integrand, $\sqrt{d x^{2}+d y^{2}+d u^{2}}=d u(1+$ $\left.\left([\mathrm{dx} / \mathrm{du}]^{2}+[\mathrm{dy} / \mathrm{du}]^{2}\right) / 2\right)+O\left[\left(\left\langle\mathrm{~b}^{2}\right\rangle / \mathrm{B}^{2}\right)^{2}\right]$, the functional integration can be performed analytically up to this $O\left[\left(\left\langle b^{2}\right\rangle / B^{2}\right)^{2}\right]$ order. Then $P(x, y, z, t)$ is to be summed over all the final values of $z$, in order to obtain the nonlocal propagator $P(x, y, t)$. Because of the very small value of $\left\langle b^{2}\right\rangle / B^{2}$, it is in fact sufficient to work to $O\left[\left\langle b^{2}\right\rangle / B^{2}\right]$. With very good accuracy the final $z$ sum can be evaluated by saddle point integration, and the result is:

$$
P(x, y, t)=\int P(x, y, z, t) d z=\frac{\Theta(t) e^{\left[\frac{-3\left(x^{2}+y^{2}\right)^{2 / 3}}{2^{2 / 3} 4 \chi_{M}^{2 / 3} x_{\|}^{1 / 3} t / 3}\right]}}{2^{2 / 3} \pi \sqrt{3}\left(x^{2}+y^{2}\right)^{1 / 3} x_{M}^{2 / 3} x_{\|}^{1 / 3} t^{1 / 3}} .
$$

Equation (11) is an exact representation of $\mathrm{P}$, but the normalization $\int \mathrm{Pdxdy}=1$, has been lost during the saddle point $z$ integration. To restore it, we have to multiply $P$ in Eq. (12) by $\sqrt{3} / 2$. Performing the poloidal average and reintroducing the proper normalization we obtain the final result :

$$
P(r, t)=\frac{\Theta(t) e^{\left[-\frac{3 r^{4 / 3}}{2^{2 / 3} 4 \chi_{M}^{2 / 3} x_{\|}^{1 / 3} t / 3}\right]}}{2 \pi 2^{2 / 3} r^{2 / 3} x_{M}^{2 / 3} x_{\|}^{1 / 3} t^{1 / 3}}
$$

Equation (13) is the main result of this letter, with Eq.(1) it solves the problem of nonlocal heat transport in a stochastic magnetic field. With this propagator the evaluation of $\left\langle\mathrm{r}^{2}(\mathrm{t})\right\rangle$ gives a value which is $\pi / 2 \sqrt{3}$ times the one obtained with the Langevin equation. In fact, without the saddle point approximation we obtain exactly the Langevin equation result.

In addition to the Langevin equation and to the Wiener integral solutions, we have performed a direct numerical simulation of heat diffusion in a stochastic magnetic field. We have studied the even moments of the radial temperature distribution when a Dirac distribution heat pulse is released on a given magnetic surface at time t equal to zero. The 
average was performed over $10^{2}$ stochastic field lines (because of the smoothing effect of parallel collisional diffusion the convergence, as a function of the number of lines, is very fast). The anomalous scaling $\left\langle\mathrm{r}^{2 \mathrm{p}}(\mathrm{t})\right\rangle \sim \mathrm{t}^{\mathrm{p} / 2}$, with $\mathrm{p}=1,2,3 \ldots$ was observed in quantitative agreement with the previous theory, and is displayed on Fig. 1. The curves have been normalized to permit their display on a single plot.

Up to now we have considered random fields of the type $b(z)$. Within the Hamiltonian picture of field line stochastic instability, $z$ is the "time", and this model is relevant. However, random magnetic fields of the type $b(x, y, z)$ are to be considered, in order to assess the influence of transverse finite correlations. ${ }^{4}$ Consider the nonlinear Langevin equations:

$$
\frac{d x}{d t}=\frac{d z}{d t} \frac{b_{x}(x, y, z)}{B}, \quad \frac{d y}{d t}=\frac{d z}{d t} \frac{b_{y}(x, y, z)}{B}, \quad \frac{d z}{d t}=\eta_{\| 1}(t),
$$

with $\left\langle b_{y}(x, y, z) b_{y}\left(x^{\prime}, y^{\prime}, z\right)\right\rangle=\left\langle b_{x}(x, y, z) b_{x}\left(x^{\prime}, y^{\prime}, z^{\prime}\right)\right\rangle=\left\langle b^{2}\right\rangle \exp \left[-\left(z-z^{\prime}\right)^{2} / 2 \lambda_{11}^{2}-\left(x-x^{\prime}\right)^{2} / 2 \lambda_{\perp}^{2}-\left(y-y^{\prime}\right)^{2} / 2 \lambda_{\perp}^{2}\right]$.

There are no general methods to solve this kind of nonlinear stochastic differential equations. This equation has some similarity with the problems of diffusion in turbulent flows, these problems have been widely studied and the observed intermittency ${ }^{15}$ can be studied with the help of multifractal measures.

In this letter we shall not carry out such a program, we shall simply apply a Gaussian approximation, of the resonant broadening type. Thus, what is expected is not only an anomalcus scaling of the mean squared displacement with respect to the time, but also with respect to the perturbating magnetic field: ${ }^{4}$

$$
\left\langle r^{2}(t)\right\rangle \sim\left[\left\langle b^{2}\right\rangle / B^{2}\right]^{\beta} t^{\alpha} .
$$

The usual $\beta=1$ quasilinear scaling is no longer valid because of the nonlinearity. To calculate $\alpha$ and $\beta$, associated with the stochastic differential equation Eq. (14), we Fourier analyze the $\mathbf{b}$ field, and perform an approximate evaluation of the resulting integral representation of $\left\langle d x / d t \cdot d x / d t^{\prime}\right\rangle$ and $\left\langle d y / d t \cdot d y / d t^{\prime}\right\rangle$, with a Gaussian assumption. 
After some calculations we obtain the following differential equation in the long time limit:

$$
\frac{\mathrm{d}^{2}\left\langle\mathrm{r}^{2}(\mathrm{t})\right\rangle}{\mathrm{dt}^{2}} \sim-\left[\frac{\left.\mathrm{b}^{2}\right\rangle}{\mathrm{B}^{2}} \lambda_{\|} \lambda_{\perp}^{2} x_{\|}^{1 / 2}\right]\left\langle\mathrm{r}^{2}(\mathrm{t})\right\rangle^{-1} \mathrm{t}^{-3 / 2} .
$$

Bohm scaling, $\beta=1 / 2$, is thus recovered but with an highly anomalous diffusion exponent $\alpha=1 / 4:\left\langle\mathrm{r}^{2}(\mathrm{t})\right\rangle \sim \lambda_{11}^{0.5} \lambda_{\perp} \chi_{\| 1}^{0.25}\left\langle\mathrm{~b}^{2}, 0.5 \mathrm{~B}^{-1} \mathrm{t}^{0.25}\right.$. This additional slowing down is due the additional $x, y$ disorder. In this regime, the calculation of the associated propagator $P$ remain an open question.

Modulation experiments and heat pulse propagation studies have been used to measure the dynamical transport responses of a tokamak plasma, i.e, the propagator $P$. These kinds of experiments seem to be the ideal tool to distinguish local and nonlocal propagators. In addition to the dynamical response we can consider also the global one, but to address the problem of the scaling of the energy lifetime, we must know the extent of the ergodic regions and the scaling of the saturated value of the turbulent field arising through the self sustainment constraint.

We have demonstrated, discussed, and checked numerically, the fact that for a wide range of tokamak parameters heat transport in a stochastic magnetic field is described by Eq. (1), where the propagator $P$ given by Eq. (13) must be used. An effective local diffusion can not be defined in this regime. The propagator behaves as $\exp \left[-\mathrm{r}^{4 / 3} / \mathrm{t}^{1 / 3}\right]$ rather than as $\exp [-$ $r^{2} / t$ ], and is independant of the very small cross field collisional diffusion.

\section{Acknowledgments}

This work was supported by the United States Department of energy under contract number DE-AC02-76-CHO3073. J.M. Rax would like to thank Professor N. Fisch for encouragement, advice, and stimulating discussions. 


\section{References}

1 M.N. Rosenbluth, R.Z. Sagdeev, J.B. Taylor, and G.M. Zaslavski, Nucl. Fusion 6, 415 (1966). N.N. Filonenko, R.Z. Sagdeev, and G.M. Zaslavski, Nucl. Fusion 7, 253 (1967). T.H. Stix, Phys. Rev. Lett. 30, 833 (1973). A.B. Rechester and T.H. Stix, Phys. Rev. Lett. 36, 587 (1976).

2 A.B. Rechester, and M.N. Rosenbluth, Phys. Rev. Lett. 40, 38 (1978). A.B. Rechester, M.N. Rosenbluth, and R.B. White, Phys. Rev. Lett. 42, 1247 (1979). A. Boozer and R.B. White, Phys. Rev. Lett. 49, 786 (1982). R.B.White "Statistical physics and chaos in fusion plasma" Horton and Reichl ed., Wiley, New York (1984). J.A. Krommes, C. Oberman and R.G. Kleva J. Plasma Phys. 30, 11, (1985). H.E. Mynick, and J.A. Krommes Phys. Rev. Lett. 43, 1506 (1987). P.H. Rebut, M. Brusati, M. Hugon and P. Lallia Nucl. Fusion Sup. 2 IAEA-CN-47/E-III-4 (1987). G. Laval, "From Particles to Plasmas", J.W. Van Dam ed., Addison-Wesley, New York (1989).

3 T.H. Stix, Nucl. Fusion 18, 354 (1978).

4 R.B. Kadomtsev, and O.P. Pogutse, Nucl. Fusion Sup. 1 IAEA-CN-37/O-1 (1979).

5 W. Feneberg, and G.H. Wolf Nucl. Fusion 21, 669 (1981). T.J. Martin, and J.B. Taylor, Plasma Phys. Controlled Fusion 26, 321(1984).

6 J.R. Albritton, Phys. Rev. Lett. 50, 2078 (1983). J.F. Luchiani, P. Mora, and J. Virmont, Phys. Rev. Lett. 51, 1664 (1985).

7 A.R. Jacobson, and R.W. Moses, Phys. Rev. Lett. 52, 2041 (1984).

8 J.M. Rax, and D. Moreau, Nucl. Fusion 29, 1751 (1989).

9 W. Young, A. Pumir, and Y. Pomeau, Phys. Fluids A 1, 462 (1989).

10 G.M. Zaslavski, R.Z. Sagdeev, D.K. Chaikovski, and A.A. Chernikov, Sov. Phys. JETP 68, 995 (1989).

11 Y. Gefen, A. Aharony, and S. Alexander Phys. Rev. Lett. 50, 77 (1983).

12 B. O'Shaughnessy, and I. Procaccia Phys. Rev. Lett. 54, 455 (1985). S. Havlin, and D. Ben-Avraham, Advances in Phys. 36, 695 (1987).

13 B.D. Hughes, E.W. Montroll, and M.F. Shlesinger J. Stat. Phys. 28,111 (1982).

B.B. Mandelbrot "The fractal geometry of nature", Freeman, New York (1983). J. Feder, "Fractals" , Plenum Press, New York (1988).

14 F.W. Wiegel Phys. Rep. 16, 57 (1974). R.P. Feynman, and A.R. Hibbs "Quantum Mechanics and Path Integrals", Mac Graw Hill, New York (1965). L.S. Schulman "Techniques and applications of path integration", Wiley, New York (1981).

15 Y.B. Zeldovich, S.A. Molchanov, A.A. Ruzmaikin, D.D. Sokolov, Sov. J.E.T.P 62, 1188, (1985). Y.B. Zeldovich, A.A Ruzmaikin, and D.D. Sokoloff," The Almighty Chance", World Scientific, Singapore (1990). 
Figure caption

Fig. 1: The first even moments $\left\langle x^{2}(t)\right\rangle,\left\langle x^{4}(t)\right\rangle,\left\langle x^{6}(t)\right\rangle$ of the temperature distribution averaged over 100 stochastic field lines, $\chi_{\| 1}=10^{S} \mathrm{~m}^{2} / \mathrm{s}, \lambda_{\|}=10 \mathrm{~m},\left\langle\mathrm{~b}^{2}\right\rangle / \mathrm{B}^{2}=10^{-6}$, in logarithmic scale. 


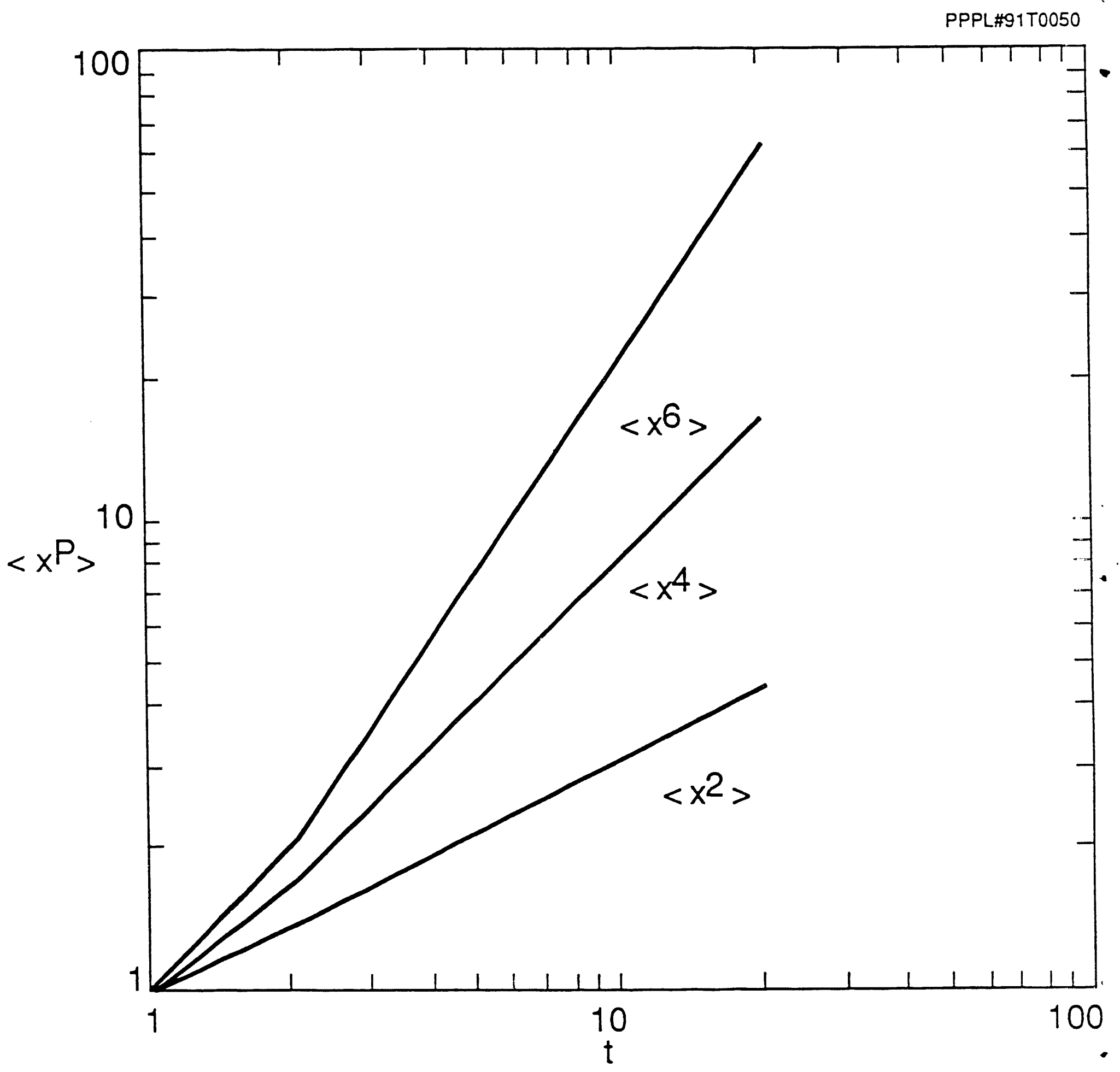


Dr. F. Proloni, Univ. a Wollongong. AUSTRALIA

Prof. M.H. Bromen, Univ. of Sydnoy, AUSTRALIA

Plasma Research Lab., Australian Nat. Univ., AUSTRALJA

Prof. I.R. Jones, Flinders Univ, AUSTRALA

Prof. F. Cap, Inst for Theoretical Physics. AUSTRIA

Prot. M. Heindler, Instiurt for Theoretische Physik, AUSTRIA

Prof. M. Goossons. Astronomisch Instituut, BELGIUM

Ecole Royalo Militaire, Lab. de Phy. Plasmas, BELGIUM

Commission-Europeen, DG. XII-Fusion Prog., BELGIUM

Prof. R. Bouciqia, Rijksuniversiteit Gent, BELGIUM

Dr. P.H. Sakanaka, Instituto Fisica, BPAZIL

Instituto De Pesquias Especiais-INPE, BPAZIL

Documents Office, Abmic Energy of Canada Lid., CANADA

Dr. M.P. Bachynakj, MPB Technologios, Inc., CANADA

Or. H.M. Skersagnd, Univ. of Saskatchewan, CANADA

Prof. J. Teichmenn, Univ. of Montreal, CANADA

Prof. S.R. Sreenivasan, Univ. of Calgary. CANADA

Prot. T.W. Johnewon, INRS-Energis, CANADA

Dr. R. Bolton, Contre canadien de fusion megnétique, CANADA

Dr. C.R. Jemes., Univ. of Aberm, CANADA

Dr. P. Lukac, Komenskeho Universzita, CZECHOSLOVAKLA

The Librerian, Culham Laboratory, ENGLAND

Library, R61. Rutherford Appleton Laboratory, ENGLAND

Mrs. S.A. Hutchinson, JET Library. ENGLAND

P. Munonen, Univ. of Helsinkj, FINLAND

C. Moubot, Lab. de Physique dos Milioux lonisés. FRANCE

J. Rader, CEN/CADARACHE - Bat 506, FRANCE

Mas. C. Rinni, Univ. of bamina, GREECE

Dr. T. Mul, Acadermy Bibliographic Ser., HONG KONG

Preprint Librery, Hungerien Acadermy of Sa., HUNGARY

Dr. B. Das Gupen Sana Inst. of Nuchear Physica. INOIA

Dr. P. Kaw, Inst, for Plasma Rosearch, INDIA

Dr. P. Posenau, lareal inst of Technology. ISRAEL

Librarian, Intermational Center for Theo Physica, ITALY

Miss C. Do Palo, Associazione EURATOMENEA, ITALY

Dr. G. Groseo, Istituto di Fisica dol Plasma, ITALY

Or. H. Yamato, Toshiba Ros \& Dovel Contor, JAPAN

Prof. I. Kowakami, Abomic Energy Res.Inst, JAPAN

Prof. K. Nishikewa, Hiroshima Univ., JAPAN
Director, Japan Abmic Energy Research Inst., JAPAN

Prof. S. Iroh, Kyustu Univ., JAPAN

Data and Planning Conter, Nagoya Univ.. JAPAN

Prof. S. Tanaka, Kyoto Univ.. JAPAN

Library, Kyoto Univ., JAPAN

Prof. N. Inoue, Univ. of Tokyo. JAPAN

S. Mori, Tectnical Advisor, JAERI, JAPAN

O. Mitara, Kumamoto Inst. of Technology, JAPAN

H. Jeong, Korea Advanced Energy Reseerch Inst., KOREA

Prot. D.I. Choi, The Korea Adv. Inst of Sa. \& Tech., KOREA

Prot. B.S. Liby, Univ. of Waiknto. NEW ZEALAND

Inst. of Plasma Physics, PEOPLE'S REPUBLIC OF CHINA

Librarian, Inat of Physica, PEOPLE'S REPUBLC OF CHINA

Library, Tainghua Univ., PEOPLE'S REPUBUIC OF CHINA

2. L. S.W. Inat Physica, PEOPLES REPUBUC OF CHINA

Prof. J.A.C. Cebrd, Inswetb Superior Tecnico, PORTUGAL

Dr. O. Potrus, AL I CUZA Univ., ROMMNIA

Dr. J. do Villiers, Fusion Sucties, AEC, S. AFAICA

Prot. M.A. Hellborg. Univ. of Nated, S. AFAICA

C.I.E.M.A.T, Fuaion Divizion Library. SPAIN

Dr. L SWmio, Univ. of UMEA, SWEDEN

Lborey. Poyd Inst of Technolooy. SWEDEN

Prof. H. Wilhomeon, Chalmers Univ. of Tech., SWEDEN

Contro Phys. Des Plasmas, Ecole Polyoch, SWITERLAND

Bibliotheek, Inst. Voor Pleame-Fyeice, THE NETHERLANDS

M. Durgut, Vico Chairmen, Midde East Tech. Univ., TUAKEY

Dr. D.D. Ayutov, Siberian Brench of Academy of Sai., USSA

Dr. G.A. Eliecev, Kurchatov Inst, USSA

Librarien, The Ukr.SSA Academy of Scionces, USSP

Dr. LM. Kovrizhnykh, Inat of Generd Physica, USSA

Komforectungeaniage GmbH. Zentrabibliothek. W. GEPMANY

Bibliothok, Inat. For Plasmaforectung. W. GERMANY

Prot. K Schinder, Auhr-Universitht Bochum, W. GERMANY

Dr. F. Wegner, (ASOEX), Max-Planck-Institurt, W. GERMANY

Librarien, Max-Planck-Institut, W. GERMANY

Prot. R.K. Janev, Inat. of Prysics, YUGOSLAVIA 

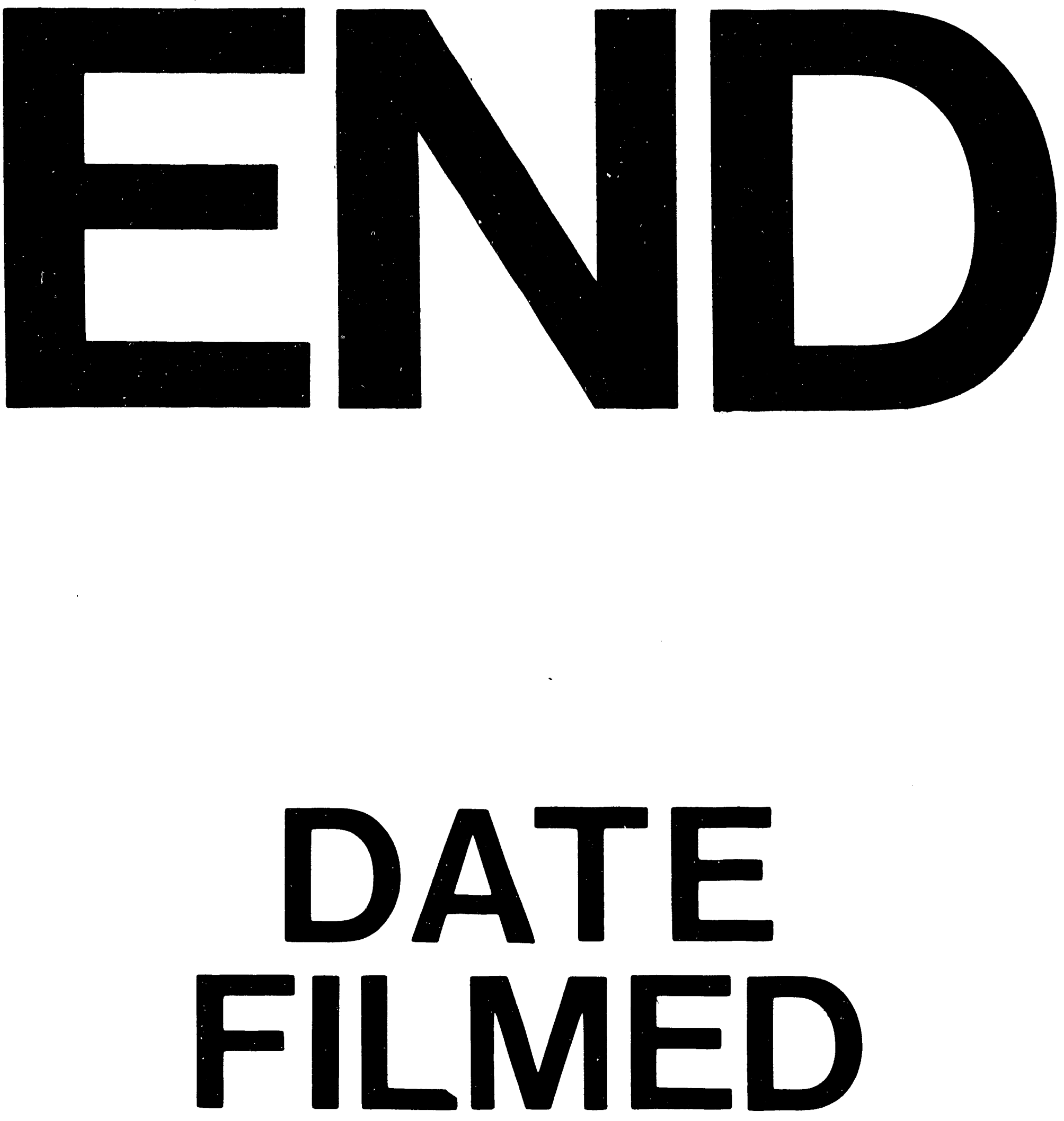

1

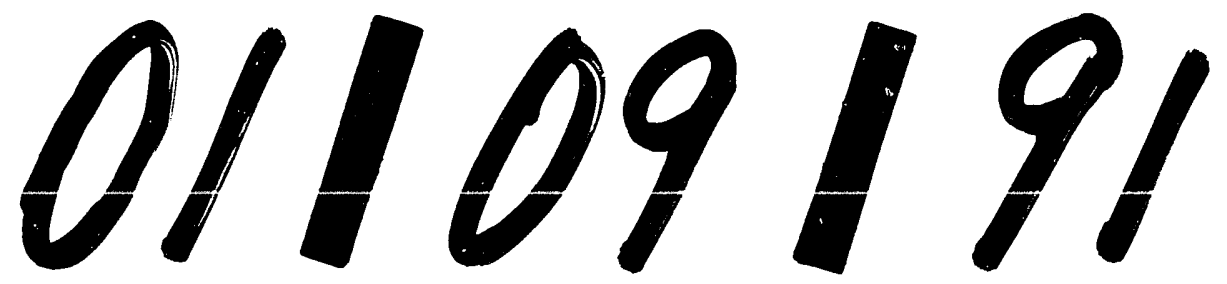


